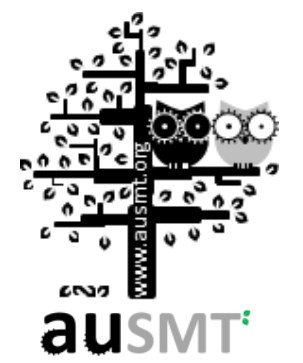

\title{
Multifunctional Inshore Survey Platform with Unmanned Surface Vehicles
}

\section{Wen-Rong Yang*, Cing-Ying Chen, Chao-Min Hsu, Chiung-Jung Tseng, and Wen-Chang Yang}

\author{
Taiwan Ocean Research Institute (TORI), National Applied Research Laboratories (NARL), Taiwan
}

(Received 9 September 2011; Published on line 1 December 2011)

*Corresponding author: allenyang@tori.narl.org.tw

DOI: 10.5875 /ausmt.v1i2.122

\begin{abstract}
Because of extreme weather and frequent natural disasters, improvement of disaster prevention capabilities and early warning technologies is an urgent matter. Inshore areas are where ocean and land intersect; the sea conditions and environment are complex and changeable, and human activities are frequent in these areas. Natural disasters, such as a substantial rise in sea levels, coastal erosion and transitions, and rapid flooding from tsunamis, and human development projects, pollution, and ecological damage must be thoroughly investigated, monitored, recorded, and prevented. The west coast of Taiwan, particularly the southeast coastal plain, is a highly populated narrow area; thus, field survey tools with a high degree of freedom and flexible applications are required for data collection to reach its full potential. The Taiwan Ocean Research Institute developed an unmanned surface vehicle (USV) for the "Long Term Observation for Research Performed in TORI" 2010 project. This USV is a platform that integrates scientific equipment, including Wi-Fi communication and a satellite-based global positioning system (GPS) with navigation images and signals, to form an internal network with onshore control bases to allow the instant acquisition of measured data and enable researchers to conduct surveys in safe conditions. USVs are appropriate for various types of inshore research and surveys, such as marine topography, sediment disposition analysis, inshore engineering measurements, and the monitoring of hydrology, water quality, and the environment. One aim of the Taiwan Ocean Research Institute (TORI) is to establish a method to use the USV for collecting inshore marine topography, hydrology, water quality, and meteorological data. Integrating field investigations of Taiwan's coastal waters will provide data for verifying numerical simulations and lead scientists to explore novel and unknown areas.
\end{abstract}

Keywords: disaster prevention; unmanned surface vehicle; GPS; inshore research

\section{Introduction}

Taiwan is surrounded by the sea; the coastline measures approximately 1,355.521 km and contains 118 major rivers, 7 major international commercial ports, 139 fishing ports, and 86 outlying islands (PengHu County, KinMen County, and MaTsu Archipelago). Domestic and international studies have indicated that global warming and ocean acidification have worsened, and extreme climate changes have increased in frequency in recent years. Additionally, coastal developmental projects and increased human-made pollution have caused changes to the marine ecosystem, reduced fishery resources, impacted economies, and affected public health. Flooding induced by the recent Japan 311 Earthquake Tsunami damaged inland Japan and resulted in loss of control over the nuclear plants. Similar to Japan, Taiwan is located on an earthquake zone, which means 23 million Taiwanese people are exposed to earthquake risks. Additionally, Taiwan's economy and public health have been affected by urban developments and increased human-made pollution; the marine ecosystem has changed and fishery resources have decreased. Driven by multiple issues, Taiwan must strengthen its disaster preparedness and response mechanisms. Observation data are conventionally obtained through sentinel surveillance buoys or oceanographic research vessels. "Taiwan Coastal Observation and Assessment 
Station (TaiCOAST)" is one subproject of the 2010 "Long Term Observation for Research Performed in TORI" by the Taiwan Ocean Research Institute (TORI). In this subproject, they cooperated with the United Ship Design \& Development Center to develop an unmanned surface vehicle (USV) named USV - ZhengHe 101. USV- ZhengHe 101 is a vehicle with integrated surveying equipment for surveying inshore waters. With significant advances in communication, positioning technology, and data transmission distance, USV-ZhengHe 101 can reduce the manpower demands of various types of data collection. USV-ZhengHe 101 is also a meteorological and hydrological mobile ocean platform that not only provides a safe operating environment, but also enables the easy integration of diverse observation equipment required to conduct specific surveillance.

Mr. Wen-Rong Yang was graduated from National Taiwan Ocean University in 1995 with a majored in Marine Chemistry. His expertise is in environmental chemistry and seawater quality. He has been involved in research projects including Chemical Hydrographic and Chlorophyll-a Characteristics in the East China Sea, KuroShio-East China Sea Shelf Exchange Processes, Long-term Observation and Research of the East China Sea. He joined Taiwan Ocean Research Institute (TORI), National Applied Research Laboratories (NARL) as an assistant Engineering in 2009. His current task is to build a National coastal seawater observation station and develop automated monitoring technology.

Chin-Yin Chen was born in TaoYuan, Taiwan, in 1976. He received his Ph.D. degree from department of mechanical and electro-mechanical engineering at the National Sun Yat-Sen University in 2008. He is currently an assistant researcher with the Taiwan Ocean Research Institute, Kaohsiung, Taiwan. His research interests include mechatronics, integrated structure/control design, and robotics.

Chao-Min Hsu joined Taiwan Ocean Research Institute (TORI), National Applied Research Laboratories (NARL) as an assistant Engineering in 2008. Before joining NARL, he was a Post Doc. at National Taiwan University from 2004-2008. His current task is to build a National coastal seawater observation station and develop automated monitoring technology.

Chiung-Jung Tseng was graduated from National Taiwan Ocean University in 2004 with a major in Marine Chemistry. Her expertise is in laboratory analysis, data quality assurance and control. She joined Taiwan Ocean Research Institute (TORI), National Applied Research Laboratories (NARL) as an assistant Engineering in 2009. She has been involved in research projects including Long-term Observation and Research of the East China Sea, assessment of potential impacts of changing river flows and water quality on coastal zone primary productivity and human health in Taiwan: the TanShui River Estuary.

Dr. Wen-Chang Yang was graduated from Chung Yuan Christian University with a B.S. degree in Hydraulic Engineering in 1981 and TamKang University with a M.S. degree in Water Resource in 1987. And his Ph.D. is completed in Department of Naval Architecture and Ocean Engineering, National Taiwan University, in 1997. After receiving his Ph.D., he went to Institute of Physics, Academia Sinica, served as a Post Doc. In this period for nearly ten years, his research work was primarily engaged in computational fluid dynamic studies and its applications including ocean outfall, jet flow, free surface problem, and nonlinear vortex mechanism etc. In 2008, he joined the faculty of Taiwan Ocean Research Institute, National Applied Research Laboratories, and worked as associate researcher to be responsible mainly for establishing HF radar system for monitoring surface current around Taiwan within four years project. Up to 2011, he was promoted as researcher and assigned as division managers of Nearshore Observation and Modeling Division and Marine Exploration Technology Division. Now there are two important observational vehicles developed for both divisions, one is Unmanned Surface Vehicle (USV) and the other is Remotely Operated Vehicle (ROV).

\section{Review of Domestic and International USV Developments and Applications}

The technical developments of USVs can be classified into two main categories: vehicle control technology and task-oriented design technology. The primary control technologies include automatic navigation systems, automatic collision avoidance systems, and intelligent control systems, for example, the swarm intelligent control technologies of some USVs. The intelligent control systems in unmanned air vehicles (UAV) and unmanned ground vehicles (UGV) have been developed for numerous years; however, USVs are more profoundly affected by sea waves and currents compared to UAVs by wind force and UGVs by ground friction force (because water density is approximately 773 times greater than air density). Therefore, special correction mechanisms are required to control the vehicle and prevent it from deviating from predetermined routes. The principle design of mission-oriented unmanned vehicles is that no personnel is onboard, which eliminates the need to comply with conventional manned ship standards and structures. USVs can be designed entirely according to the mission requirements to conduct operations under adverse sea conditions and in areas that unsafe for manned vehicles.

A USV developed under the leadership of the Office of Naval Research (ONR) in 1990 [1] was originally named an "autonomous search and hydrographic vehicle (ASH)," but was later renamed "Owl." The total length of the Owl is $3 \mathrm{~m}$, maximum speed is 45 knots, and cruising endurance is $10 \mathrm{hrs}$. (at 12 knots) and $24 \mathrm{hrs}$. (at 5 knots); the vehicle draft is only $18 \mathrm{~mm}$, and can travel in relatively shallow inshore waters. Owls are primary used to conduct minefield reconnaissance, shallow water monitoring, maritime interception, and safeguard ports and surrounding areas. The loading capacity of an Owl is $200 \mathrm{~kg}$ and the primary equipment loaded includes front view and side-scan sonars, night/day/infrared cameras, and laser range finders. Owls use commercial GPS for navigation and tracing, and single-frequency radio communication equipment for telemetering, controlling and transmitting data, and uploading data to the control center to provide instant image information. Owls are USVs designed specifically for the battle front; it is mainly used for strategic applications such as intelligence, surveillance, and reconnaissance (ISR) and antisubmarine missions [2]. Other countries around the world have also successively researched and developed vehicles with different features, for example, vehicles that are high-speed and lightweight, for guerilla or luring purposes, or that can become invisible or used for training. Vehicles have also been equipped with various 
communication intelligence systems, such as systems for electronic interference, photoelectric sensors, detection equipment, and light weapons. Please refer to Figure 1 and the descriptions for information on additional USV designs.

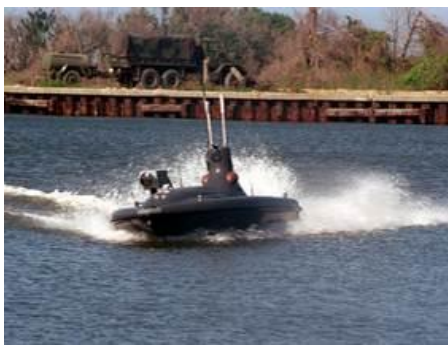

Autonomous search and hydrographic vehicle (ASH) for reconnaissance, 1990, U.S.A. ONR

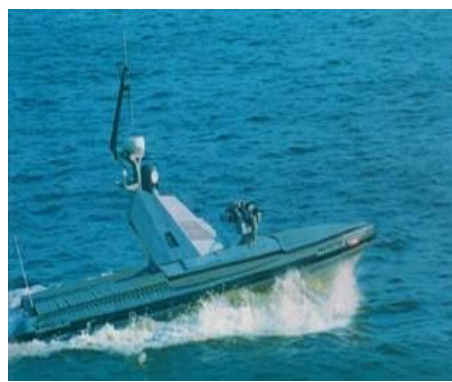

Protector USV for reconnaissance, counter-mine warfare, and electronic warfare, 2003, Israel

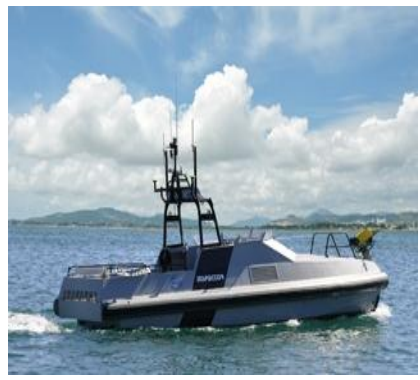

Inspector USV for shore patrol, antisubmarine, and

reconnaissance, 2007, France

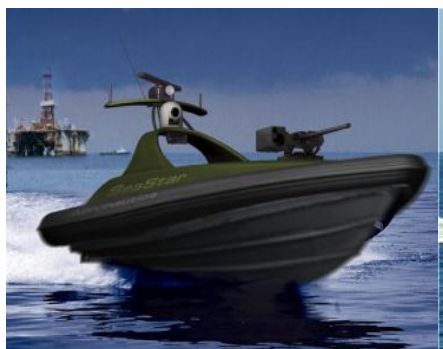

Seastar USV for strategy, patrols, reconnaissance, interference and decoy, and extended optical magnetic field, Israel
Regarding scientific applications, the Commission of the European Communities initiated the ASIMOV development project [8] in 1983, which emphasized ocean observations and data transmission research.

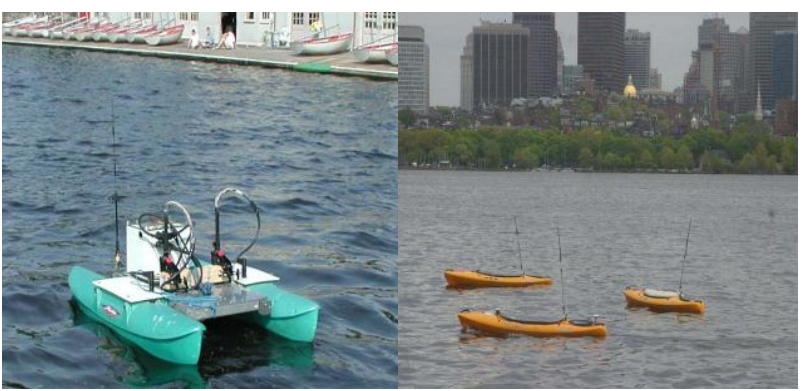

Autonomous coastal exploration system (ACES) for autonomous inshore

Kayak with underwater sonar counter-mine and antisubmarine applications, 2001, U.S.A. ONR

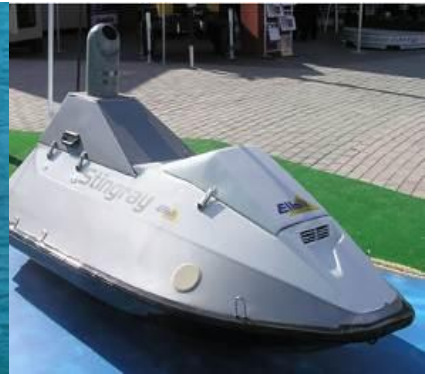

Stingray autonomous navigation, for electronic reconnaissance and electronic warfare, 2005 , Israel

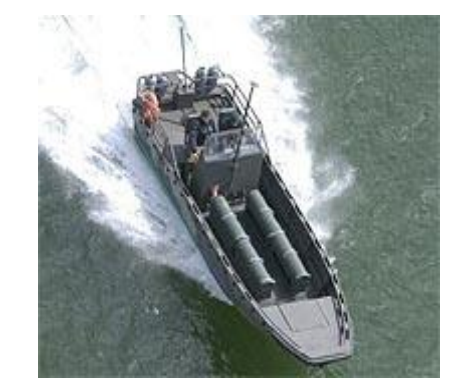

M8 USV fast attack craft, 2008, German Navy

exploration, 1996, U.S.A. MIT

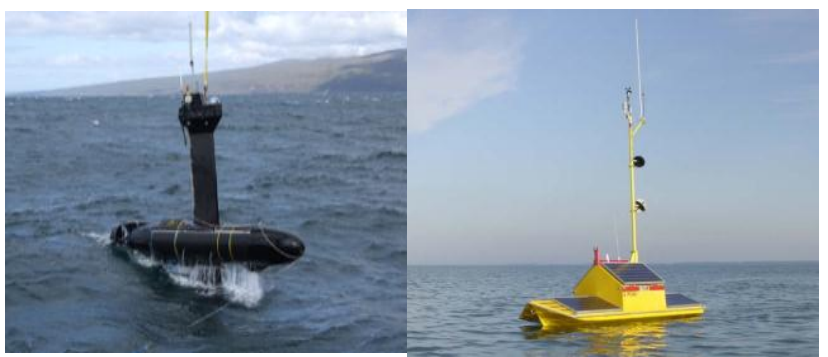

Survey autonomous Ocean Atmosphere Sensor Semi-Submersible (SASS) 6M MK2 for semi-submersible environmental monitoring, Integration System (OASIS) for long-term measurement of hydrology and carbon dioxide 2006, Plymouth University, U.K. gas-water flux, 2006, U.S.A. NOAA

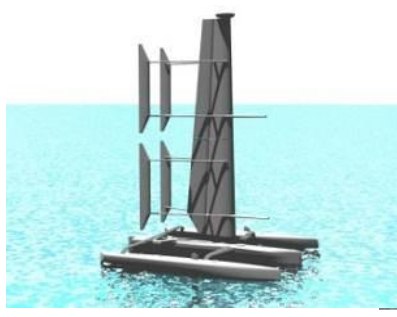

HWT X-1 wind-driven trimaran capable of cruising over 30 days, 2007, U.S.A. Harbor Wing Tech.

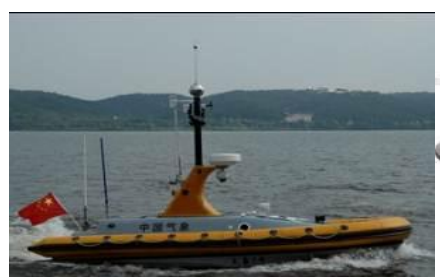

Planetarium 1 with a weather detection system, 2008, China Aerospace Science and Industry, Co.

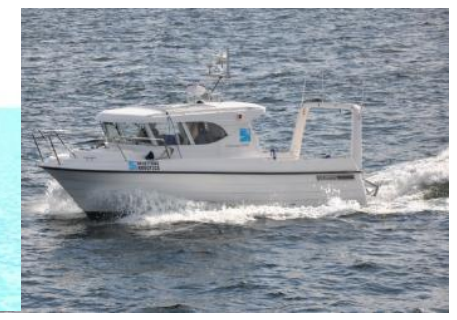

Viknes USV for multipurpose tests, 2008, Norwegian University of Science and Technology

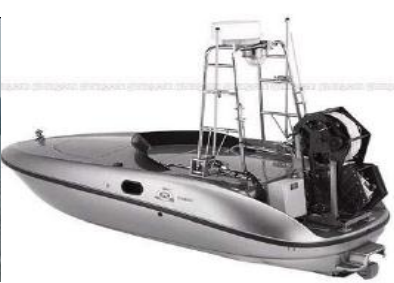

UMV-O for ocean exploration, Yamaha, Japan composites) for reconnaissance 2010, U.S.A.

Zyvex Technologies 
Since then, marine science applications, such as topography surveys and environmental monitoring have been used to develop USVs with various functional features, for example, catamarans, semi-submersible vessels with improved stability and greater wave resistance, combined with solar energy for long-term observations [16]. The National Oceanic and Atmospheric Administration (NOAA) developed three small autonomous surface crafts in 2006; these crafts are powered by solar energy and equipped with an Ocean Atmosphere Sensor Integration System (OASIS) for the long-term measurement of hydrological data and the carbon dioxide gas-water flux. The craft with an OASIS is approximately $6 \mathrm{~m}$ long and contains equipment for measuring temperature, salinity, chlorophyll, depth, dyes, and Acoustic Doppler Current Profiler (ADCP) sensors for scientific experiments (Higinbotmam et al.) [10]. In addition to academic research applications, USV have also been developed for industrial applications. SeaRobotics Corporation of the U.S. has developed a series of remotely operated USVs, including USV-450, USV-600, USV-1000, USV-2600, and USV-5000. In these USVs, an ADCP, a conductivity, temperature, and depth (CTD) sensor, multibeam bathymetry, and side-scan sonar can be installed and remotely controlled by radio for remote investigations, measurements, environmental data sampling, monitoring and surveillance. Please refer to the images and descriptions in Figure 2 regarding the development and application of USVs in other scientific fields.

By contrast, USV-related information is scarce in Taiwan and only a few example applications on lakes and reservoirs are available. The lack of UVS-related information is because of the following several factors: Taiwan conducts limited independent research and development of oceanographic survey equipment; maritime activities are inconvenient despite being surrounded by ocean waters; the lack of development has resulted in a small market for the equipment; and imported equipment is expensive and academic research funding is frequently limited. The focus of marine scientific research has gradually shifted from military purposes to global environmental changes and disaster prevention in the new century. Because Taiwan is an island that "prospers by the maritime industry," it has the potential to thrive in this industry through integrating its abundant resources with telecommunication hardware and software, and yacht designs and manufacturing.

\section{Vehicle Designs}

Because of the necessity for coastal marine measurements, USVs must be at least equipped with the following special functions/specifications:

(1) Shallow load drafts: To comply with the requirements for inshore measurements, and to account for the tide range, the load draft of the vehicle cannot be excessively deep to allow performance in inshore areas and to reduce the limitations caused by ebbs.

(2) Automatic navigation systems: To comply with the measuring requirements, vehicles must sail according to the designated coordinates to allow measurements of specific spatial locations.

(3) Sufficient loading and cruising endurance: Vehicles must have sufficient distance endurance to complete measuring missions and have adequate load capacity for carrying equipment and providing power to the equipment.

(4) Appropriate speed and control: Vehicles must have sufficient power to resist waves, tides, and currents while controlling the hull within the measuring range. Vehicle speed must also be controlled in compliance with the sensitivity and required time of measuring equipment.

We have designed an experimental USV according to the specified special functional requirements to test the feasibility and cost-effectiveness of using USVs for various measurements in inshore areas in Taiwan. Current USV designs are modified based on conventional work ships, as shown in Figures 3 and 4. The design specifications are as follows:

Length: $5.0 \mathrm{~m}$

Beam: $1.9 \mathrm{~m}$

Depth: $0.83 \mathrm{~m}$

- Full load draft: $0.26 \mathrm{~m}$

- $\quad$ Displacement: $945 \mathrm{~kg}$

- Loading capacity: $250 \mathrm{~kg}$

- Horsepower of the main engine: $70 \mathrm{hp}$

- Maximum speed: 8 knots

- Fuel and capacity: $70 \mathrm{~L}$ of diesel

- $\quad$ Cruising endurance: at least $8 \mathrm{hrs}$. when traveling below 4 knots

- Battery capacity: 12 V 200 Ah, 3 lead-acid batteries

- Wireless communication interface: Wi-Fi, with a transmission distance of 5 nautical miles $(\mathrm{nm})$

Navigation sensor: electronic compass $\mathrm{X} 1$ and GPSX1 
The vehicle is controlled by shore-based remote operation. Onshore operators issue throttle and steering commands (Figure 5) that are transmitted to the onboard host computer through $\mathrm{Wi}-\mathrm{Fi}$ internet transmission; the onboard host computer subsequently controls the throttle and the steering engine. Additionally, the host computer also transmits the shipping course (according the electronic compass signals), the location (according to GPS signals), the fuel volume, the electric quantity of the vehicle to the computer onshore for the operators' reference. The human-machine interface is shown in Figure 6.

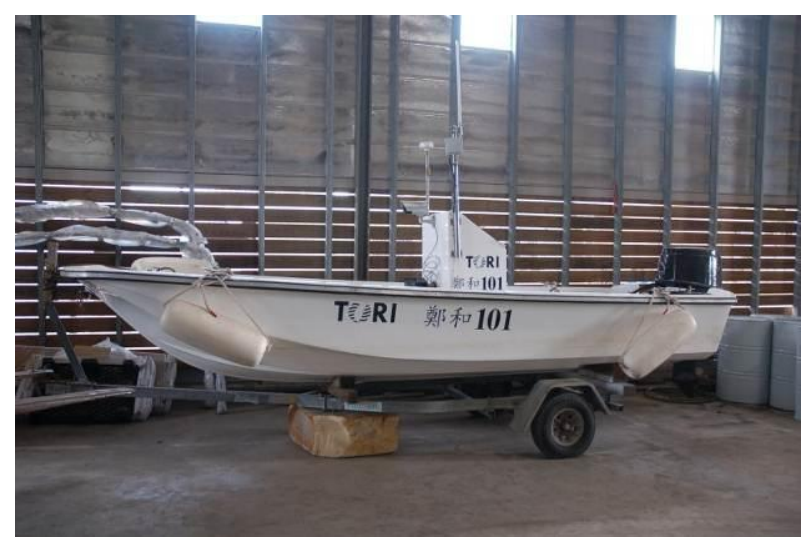

Figure 3. An unmanned surface vehicle cooperatively developed by the Taiwan Ocean Research Institute and the United Ship Design \& Development Center.
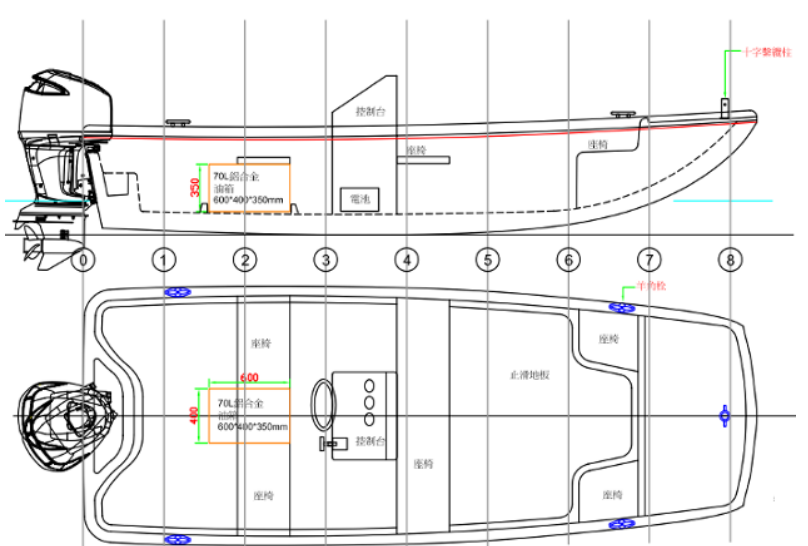

Figure 4. General layout of unmanned vehicles.

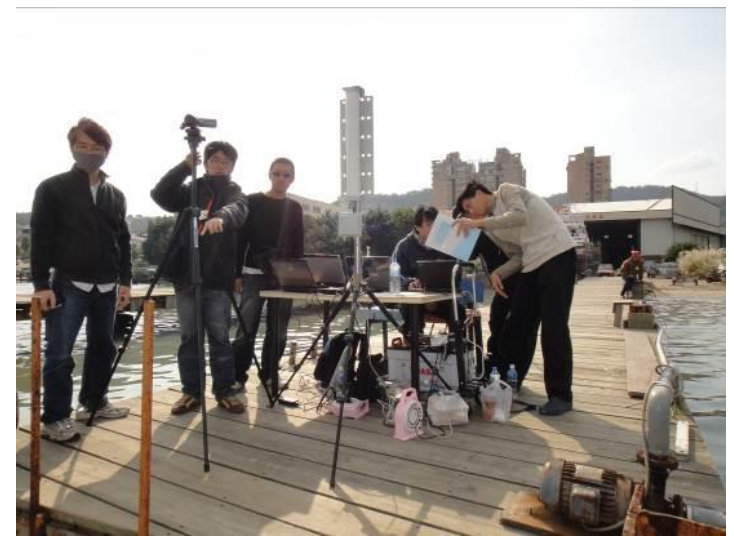

Figure 5. Shore-based remote control operation.

www.ausmt.org

Copyright (C) 2011 International Journal of Automation and Smart Technology

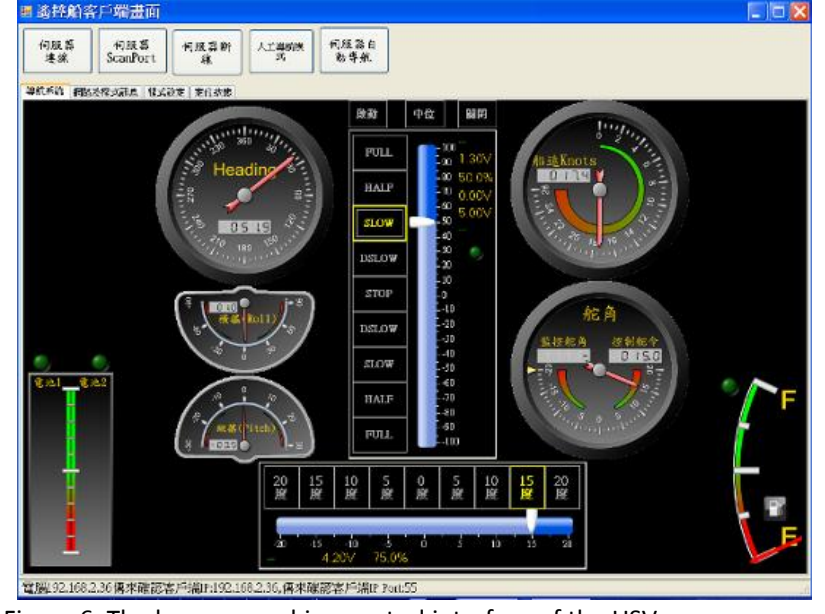

Figure 6. The human-machine control interface of the USV.

\section{The Payload of Frequently Used Equipment and Applications in Marine Surveys}

Because USV designs are not required to consider the weight of human operators, the $250 \mathrm{~kg}$ payload can be used entirely by measurement equipment; thus, USVs can carry more equipment compared with workboats of the same size. The integration of miscellaneous equipment allows USVs to function as integration platforms (Figure 7). Equipment frequently used in marine surveys (Figure 8) includes side-scan sonars, sonar echo sounders, sub-bottom profilers, and magnetometers. Side-scan sonars are employed to scan seabed images of large areas [5], distinguish seabed structures, contribute to marine archaeology, search for sunken ships, lay submarine pipeline or cables, and provide direct images for fishery and underwater ecological environmental studies, dredging projects, and mine detections. Single beam or multibeam sonar echo sounders provide accurate 3D data for water depth and topography surveys, and are indispensable in marine engineering applications. Sub-bottom profilers provide images of the sediment structures below the seabed and are useful for locating dip faults and estimating the seabed resource of petroleum and natural gas. Finally, magnetometers are used for detecting metals on the seabed when, for example, mining metal ore or searching for under seabed cables or sunken ships.

Furthermore, hydrological and water quality survey equipment, such as ADCPs, measure the flow velocity and flow direction at different water layers, the onboard underway CTD provides information of seawater features, and the meteorological equipment measures the gas-water flux. 


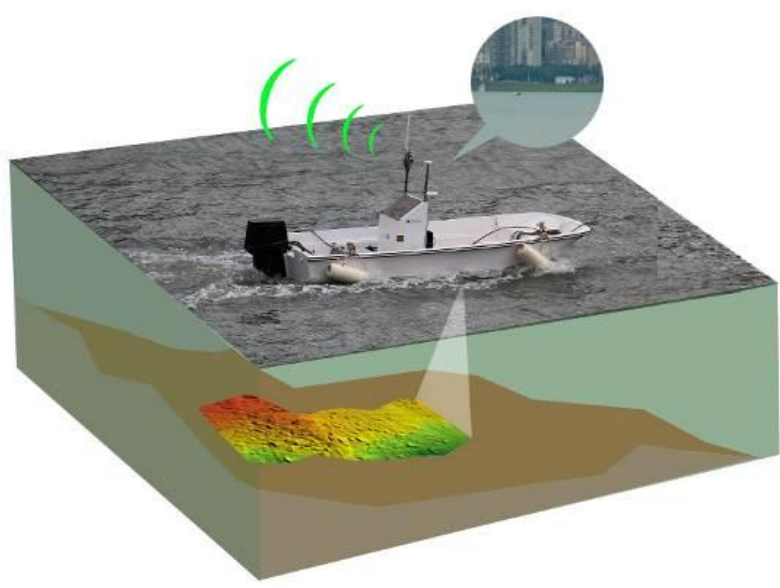

Figure 7. A schematic diagram of integrated oceanographic survey mission equipment.

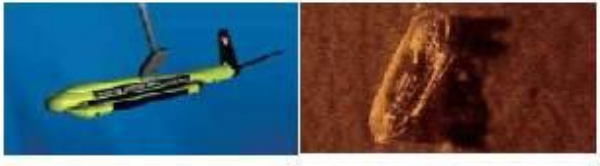

Side Scan Sonar Imager

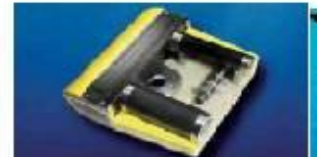

Multi Beam Echo Sounder

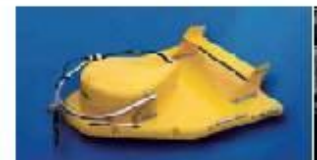

SUB Bulturiı Profiler

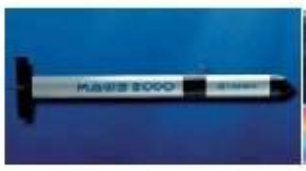

Magneloineler

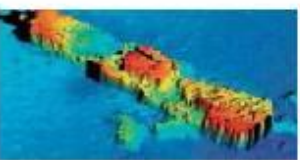

Bathymetry

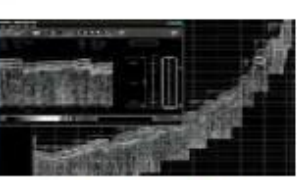

Sediment Analysis

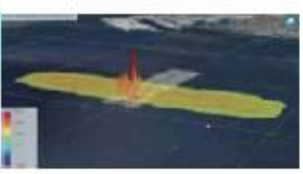

Magnctic Mapping

Figure 8. A variety of frequently used marine survey equipment.

\section{Operation Measurements}

Following completion, we tested the vehicle multiple times at the estuary of TamSui River. The testing conditions were normal and the vehicle performance met expectations.

For speed tests, the average velocity of the vehicle traveling between two flags $175 \mathrm{~m}$ apart reached 10.6 knots, achieving the design requirement. At one quarter advancing, the left whirl took $46 \mathrm{~s}$, and the whirl diameter was $9.1 \mathrm{~m}$; the right whirl took $47 \mathrm{~s}$ and the whirl diameter was $11.2 \mathrm{~m}$. In other words, the vehicle is agile because the space available to whirl was only approximately twice the length of the vehicle.

Signal transmissions were normal in unshielded open water; images were transmitted onshore in real-time as auxiliary information for the operators to control the sailing direction and avoid collisions. Figures 9 to 12 show GPS trace diagrams and a USV during a sea trial.

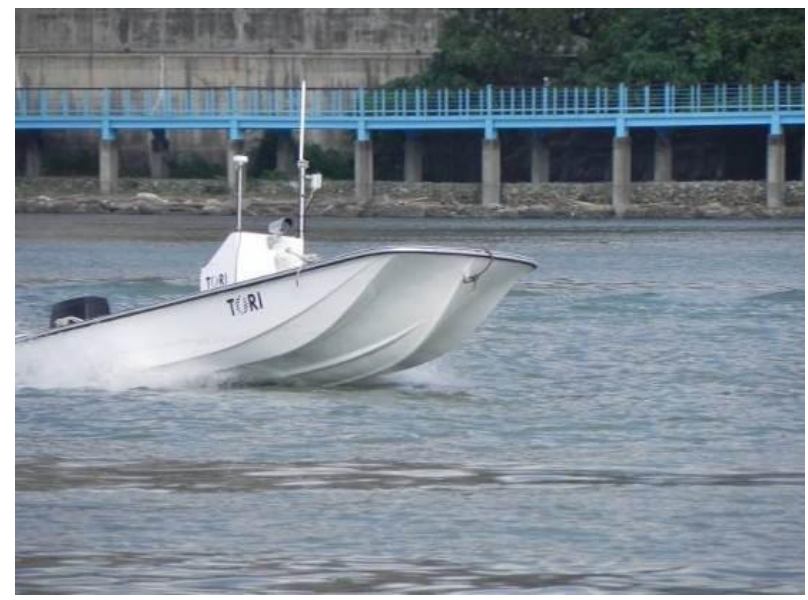

Figure 9. USV-ZhengHe 101 at the estuary of Tamsui River.

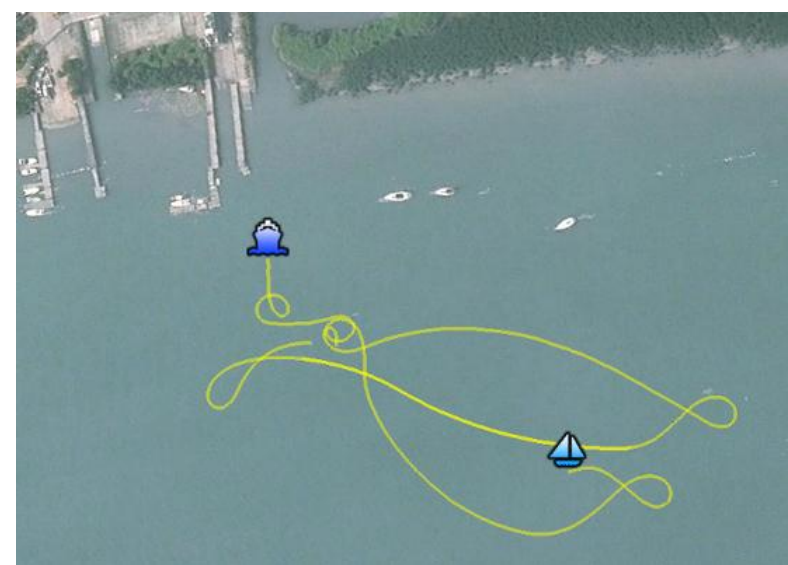

Figure 10. A GPS trace diagram (sketched using Google earth).

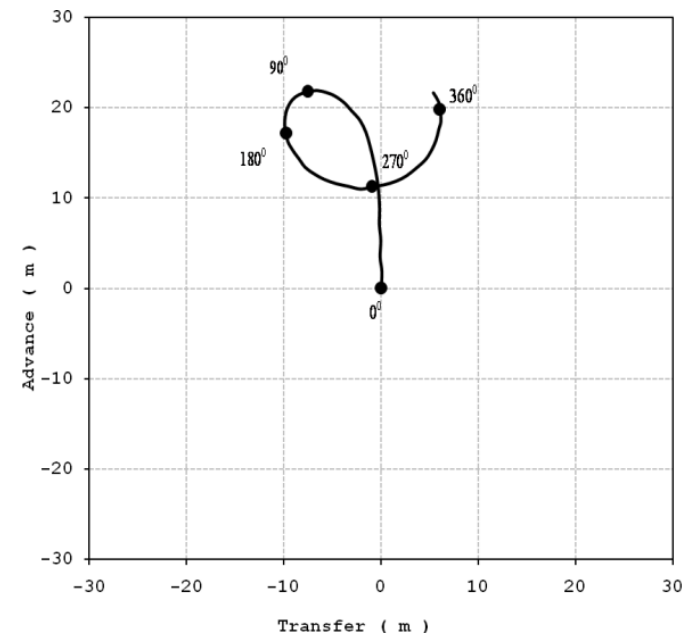

Figure 11. A cyclotron trace diagram. 


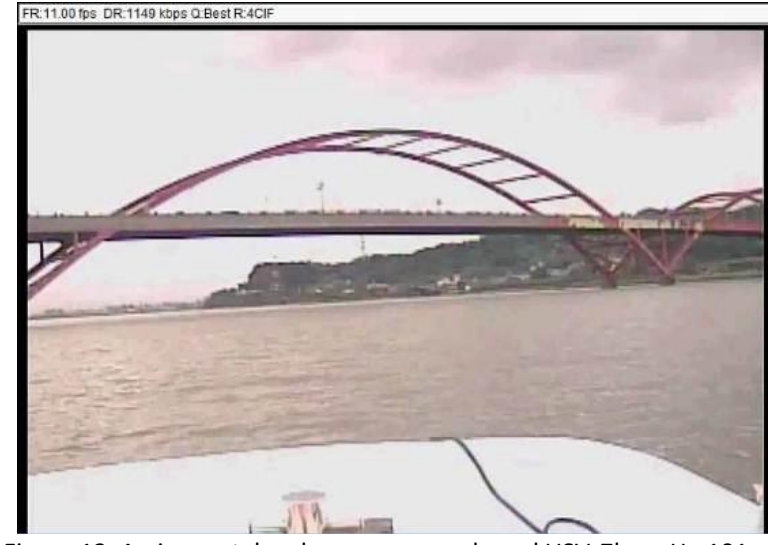

Figure 12. An image taken by a camera onboard USV-ZhengHe 101.

\section{Conclusion}

This study introduces an integrated platform of scientific equipment, a USV, developed by the Taiwan Ocean Research Institute. The USV contains equipment that complies with the requirements for inshore measuring missions. The USV was tested at the estuary of TamSui River to simulate mission operations. The onshore-based operation station received measurement data and images in real-time while the USV sailed. An expanded measuring range and prolonged operation duration are anticipated improvements that would enable greater data collection.

Future directions for this research include developing unique USVs specifically for various ocean observation missions, such as long-term observations and inshore disaster prevention technology improvements, to assist in scientific research, marine engineering, and homeland security missions.

\section{Acknowledgement}

We thank Mr. Wen-Hua Pan of United Ship Design \& Development Center and his team and TaChou Ship Bldg. Co., Ltd. for their engineering assistance. We also thank the Director of TORI for his guidance and encouragement, and our colleagues Yuan-Xiang Cai, Zhi-Kai Hu, Ji-Zhuang Wu, Si-Hua Chen, Li-Wen Wang, Xue-Rong Li, Shi-Rong Li, Fang-Xu Guo, and Jun-Jie Huang for their support and assistance.

\section{References}

[1] V. Bertram, "Unmanned surface vehicles-a survey," presented at the Skibsteknisk Selskab, Compenhagen, Denmark, 2008.

[2] "The navy unmanned surface vehicle (USV) master plan," The United States Navy, 2007. Available: http://www.navy.mil/navydata/technology/usvmp pr.pdf
[3] Defense Update. (2006). Stingray. Available: http://www.defense-update.com/products/s/sting ray.htm

[4] ECA Robotics. INSPECTOR-unmanned surface vehicle for seabed mapping surveys. Available: http://www.eca-robotics.com/en/robotic-vehicle/r obotics-naval-usv-inspector-unmanned-surface-ve hicle-for-seabed-mapping-surveys/68.htm

[5] S. Writers, SpaceDaily. (2008). Floating steel: Rheinmetall develops USV for german navy. Available:

http://www.spacewar.com/reports/Rheinmetall D evelops USV For German Navy 999.html

[6] Aeronautics Ltd. Seastar USV. Available: http://aeronautics-sys.com/seastar unmanned su rface vehicle usv

[7] Zyvex Marine and Zyvex Technologies. Piranha USV. Available: http://www.zyvexmarine.com/piranha/

[8] A. Pascoal, P. Oliveira, C. Silvestre, L. Sebastiao, M. Rufino, V. Barroso, J. Gomes, G. Ayela, P. Coince, M. Cardew, A. Ryan, H. Braithwaite, N. Cardew, J. Trepte, N. Seube, J. Champeau, P. Dhaussy, V. Sauce, R. Moitie, R. Santos, F. Cardigos, M. Brussieux, and P. Dando, "Robotic ocean vehicles for marine science applications: The European ASIMOV project," in OCEANS, Providence, RI, 2000, pp. 409-415. doi: 10.1109/OCEANS.2000.881293

[9] M. Breivik, "Topics in guided motion control of marine vehicles," Ph.D. dissertation, Department of Engineering Cybernetics, Norwegian University of Science and Technology, 2010.

[10] J. R. Higinbotham, J. R. Moisan, C. Schirtzinger, M. Linkswiler, J. Yungel, and P. Orton, "Update on the development and testing of a new long duration solar powered autonomous surface vehicle," in OCEANS, Quebec City, QC, 2008, pp. 1-10. doi: 10.1109/OCEANS.2008.5152048

[11] J. Curcio, J. Leonard, and A. Patrikalakis, "Scout-a low cost autonomous surface platform for research in cooperative autonomy," in OCEANS, 2005, pp. 725-729.

doi: 10.1109/OCEANS.2005.1639838

[12] Harbor Wing Technologies, Inc. Harbor wing AUSV. Available:

http://www.harborwingtech.com/products.htm

[13] Autonomous Surface Vehicles. SASS 6M MK2. Available:

http://www.asvglobal.com/html/survey and surv eillance vehicl.html

[14] J. S. Zhao, (2008). Planetarium 1. Available: http://scitech.people.com.cn/BIG5/7756421.html

[15] J. E. Manley, "Development of the autonomous surface craft "ACES"," in OCEANS, Halifax, NS , Canada, 1997, pp. 827-832. doi: $10.1109 /$ OCEANS.1997.624102

[16] S. L. Wood, "Application of an autonomous self-mooring vehicle," Sea Technology, vol. 50, no. 1.

auSMT Vol. 1 No. 2 (2011) 